\title{
PROMOÇÃO DA SAÚDE NO CENÁRIO RELIGIOSO: possibilidades para o cuidado de enfermagem
}

A driana G omes N ogueira FE R RE IRA a, Fabiane do A maral GU BE RT b ${ }^{\mathrm{b}}$, Alissan Karine Lima M A RT IN Sc, M arli Teresinha G imeniz G ALVÃ ${ }^{d}$, N eiva F rancenely Cunha VIEIRA e, Patrícia N eyva da Costa PIN HEIR ${ }^{f}$

\section{RESUMO}

Estudo qualitativo, do tipo documental, desenvolvido no primeiro semestre de 2008, objetivando descrever as práticas de promoção da saúde desenvolvidas no cenário religioso católico em município do interior do Ceará. As informações foram col etadas por meio de entrevistas áudio-gravadas, junto ao sacer dote responsável pela paróquia e a três coordenadores de projetos vinculados à I greja Católica, selecionados a partir da identificação dos projetos com o pároco. Os resultados apontam que a promoção e educação em saúde estão presentes nas atividades desenvolvidas por voluntários no cenário religioso. A I greja busca a mudança de atitude e adoção de comportamento saudável dos indivíduos, por meio de ações individuais e coletivas. U rge necessidade da inserção de profissionais de saúde para atuar neste cenário, fortalecendo-o como rede social de apoio, reduzindo gradativamente atividades assistenciais e intensificando aquelas voltadas à promoção da saúde, com apoio da Enfermagem, com vistas a aprimorar o cuidado à saúde neste cenário.

D escritores: Promoção da saúde. Cuidados de enfermagem. E ducação em saúde. Religião.

\section{RESUMEN}

E studio cual itativo, detipo documental, desar rollado en el primer semestre de 2008, con el objetivo de describir las prácticas de promoción de la salud desarrolladas en un ambiente religioso en municipio del interior de Ceará, B rasil. L as informaciones fuer on colectadas por medio de entrevistas audio- grabadas, junto al sacerdote dela par roquia y tres coordinadores de proyectos. L os resultados indican que la promoción y educación en salud están presentes en las actividades desar rolladas por voluntarios en un ambiente religioso. L a iglesia busca un cambio de actitud y la adopción de comportamientos saludables delos individuos, por medio de acciones individuales y colectivas. U rge la necesidad de inserción de profesional es de salud para actuar en este ambiente for taleciéndolo como red social de apoyo, reduciendo actividades asistenciales e intensificando la promoción de la salud, con apoyo de la E nfermería, buscando perfeccionar el cuidado en este ambiente.

D escriptores: Promoción dela salud. A tención de enfer mería. E ducación en salud. Religión. T ítulo: P romoción de la Salud en un ambiente religioso: posibilidades para el cuidado de enfermería.

\section{ABST RACT}

This was a qualitative study of the documentary type carried out in the first half of 2008 , and it aimed to describe the practices of health promotion devel oped in the religious scenario in a city in the countr yside of Ceará, B razil. I nformation were collected through audio-taped interviews with the priest in charge of the par ish and thethreecoordinators of projects linked to the Catholic Church, selected by the identification of projects with the priest. The results show that promotion and health education are present in the activities devel oped by volunteers in the religious scenario. The church seeks to change attitudes and to promotethe adoption of healthy behavior by individuals, through individual and collective actions. There is an urgent need to insert healthcare professionals in this scenario, strengthening it as a social support, gradually reducing theassi stential activities and intensifying those aimed at health promotion with the support of nursing, in order to improve healthcarein this scenario.

Descriptors: $\mathrm{H}$ ealth promotion. $\mathrm{N}$ ursing care $\mathrm{H}$ ealth education. R eligion.

$\boldsymbol{T}$ itle: $\mathrm{H}$ ealth promotion in the religious scenario: opportunities for nursing care

\footnotetext{
a M estre em Enfermagem, D outoranda pelo Programa de Pós-G raduação em Enfermagem da U niversidade Federal do Ceará (U FC), Professora Colaboradora da U niversidade E stadual Vale do A caraú (UVA) e do Instituto Superior de T eologia A plicada (INTA), Bolsista da Coordenação de A perfeiçoamento de Pessoal de Nível Superior (CAPES), Sobral, Ceará, Brasil.

${ }^{b}$ D outora em Enfermagem, Professora A ssistente da U niversidade Federal do Piauí (U F PI), F Ioriano, Piauí, Brasil.

c M estre em Enfermagem, D outoranda pelo Programa de Pós-G raduação em Enfermagem da U FC, Professora Assistente da U niversidade Federal de Campina Grande (U F CG ), Cajazeiras, Paraíba, Brasil.

d D outora em D oenças T ropicais, D ocente do Programa de Pós-G raduação em Enfermagem da U FC, Fortal eza, Ceará, Brasil.

e PhD em E ducação em Saúde, D ocente do Programa de Pós-G raduação em Enfermagem da U FC, Pesquisadora do Conselho N acional de Desenvolvimento Científico e T ecnológico (CN Pq), Fortaleza, Ceará, Brasil.

f D outora em Enfermagem, D ocente do Programa de Pós-G raduação em Enfermagem da U FC, Fortal eza, Ceará, Brasil.
} 


\section{INT RODUÇÃO}

Ao refletir acerca da Promoção da Saúde no cenário religioso, vale considerar as diferenças conceituais existentes entre religiosidade e espiritual idade. Distingue-se religiosidade como a adesão às crenças e práticas relativas a uma igreja ou instituição religiosa organizada; e espiritualidade como a relação estabel ecida entre a pessoa e uma força superior na qual ela acredita ${ }^{(1)}$. A evidência da importância de tal abordagem se deu em estudo com pacientes de diálise, em que a espiritualidade e religiosidade foram relacionadas principalmente com aspectos de qualidade de vida e enfrentamento da doença, sendo um ponto passível de ser considerado pelos profissionais de saúde(2).

$\mathrm{N}$ este estudo, abordou-se o conceito de religiosidade sob uma perspectiva sociocultural: a adesão à crença e prática relativa a uma igreja ou instituição, porquanto esta pode interferir em comportamentos e respostas de cada indivíduo nos processos de saúde-doença, ancorados nos diversos contextos que per meiam esta realidade ${ }^{(3)}$.

E $m$ relação às ações de saúde nas quais a I greja Católica está envolvida, estas vão além de cuidados espirituais de seus fiéis, e são fundamentadas pelas Diretrizes G erais da A ção Evangelizadora da I greja no Brasil. Segundo o documento, a I greja Católica tem papel essencial frente às políticas públicas e, ao mesmo tempo, estabelece presença solidária junto aos pobres e excluídos, como efetiva participação face as necessidade humanas básicas, entre elas a saúde ${ }^{(4)}$.

D eter minados motivos justificam o interesse do estudo junto a I greja como espaço promotor da saúde, principalmente relacionados à experiência que o processo saúde-doença acarreta em cada pessoa, podendo causar sofrimento físico e psíquico. Diante do sofrimento, 0 indivíduo volta-se à religiosidade como apoio no enfrentamento da doença, favorecendo assim seu bem-estar ${ }^{(1)}$ e o fato marcante das pessoas passarem grande parte do tempo vivendo em grupo, desde um pequeno núcleo familiar até associações, turmas, etc. $N$ esse sentido, a I greja apresenta-se como local onde as atitudes positivas e de compromisso com o outro é marcante, favorecendo a formação de redes e a existência de ações inter setoriais $s^{(5,6)}$.

A religião cumpre um papel facilitador para 0 acesso a redes de suporte e integração social por meio de suas instituições religiosas e congrega- ções ${ }^{(1)}$. E stas participações fortalecem as redes de apoio, a partir da compreensão de rede como um sistema complexo, considerado como um fato social, onde promove a reflexão acerca das práticas cotidianas e a realidade social ${ }^{(7)}$.

A I greja em sua essência, assume o papel de rede de apoio social com a finalidade de contribuir com o bem estar das pessoas, principalmente em situação de exclusão, permitindo a possibilidade do exercício da cidadania ${ }^{(8)}$.

Para atender adequadamente às necessidades de saúde da população, se faz necessário contemplar as múltiplas interconexões socioculturais que existem entre usuários dos serviços de saúde, profissionais de saúde e comunidade, considerando que o estado de enfer midade/ doença é determinado pela experiência subjetiva dos sujeitos enquanto membros da comunidade mais do que pel os aspectos clínicos e físicos ${ }^{(7)}$.

Promoção da saúde é o processo de capacitação e fortalecimento da comunidade, envolvendo ações dirigidas à melhoria da qualidade de vida e que per mitam a participação desta no controle das intervenções ${ }^{(8,9)}$. A ideia de promoção da saúde envolve 0 fortalecimento da potencialidade individual e coletiva para lidar com a multiplicidade dos condicionantes de saúde ${ }^{(10)}$.

Como profissão, ao atuar com vistas à promoção da saúde, a Enfermagem comprometida com 0 cuidado holístico deverá estar sensível às necessidades espirituais dos seus pacientes, pois a minimização ou negligência deste aspecto poderá acarretar grandes complicações no processo adaptativo de adoecimento ${ }^{(11)}$.

Nesta perspectiva, conhecendo o papel decisivo da I greja na promoção, prevenção, educação e reabilitação com vistas a fortalecer a autonomia dos indivíduos, famílias e comunidades, este estudo tem o objetivo de descrever as práticas de promoção da saúde desenvolvidas numa I greja Católica em município do interior do Ceará.

\section{METODOLOGIA}

Estudo descritivo de abordagem qualitativa, do tipo documental, ou seja, aquela que se utiliza fundamentalmente de materiais que não receberam tratamento analítico, ou que podem ser reelaborados de acordo com o objeto de estudo e onde as fontes poderão ser diver sificadas ${ }^{(12)}$. N este caso consideraram-se os documentos que não receberam 
tratamentos analíticos, tais como: relatórios, ata de reuniões, regimentos inter nos dos projetos identificados.

O estudo foi desenvolvido na Paróquia de Sant'A na, no município de T ianguá, Ceará, localizado a 320 quilômetros da cidade de Fortaleza. Participaram como sujeitos da pesquisa o pároco da Paróquia e os coordenadores de projetos e atividades realizadas por esta paróquia, vistos como promoção da saúde. No total, quatro sujeitos (pároco e coordenadores) participaram do estudo. A pesquisa foi realizada no período de abril e junho de 2008, A coleta de informações ocorreu por meio de entrevista e leitura de documentos fornecidos pela instituição acerca dos projetos de saúde, a fim de conhecer as intervenções realizadas.

Para a seleção dos sujeitos inicialmente foi feito contato com o sacerdote responsável pelas ações da I greja Católica no município, seguido da identificação dos projetos e consequente busca de seus coordenadores. Os critérios de inclusão adotados foram pessoas que coordenassem os projetos indicados pelo pároco e que aceitassem participar do estudo.

A primeira fase do estudo contou com a coleta de informações mediante entrevista com os participantes, mediada pela seguinte questão norteadora: Pode me dizer se existem atividades relacionadas à saúde nesta paróquia? E m caso afirmativo, continuamos perguntando: Pode me descrever como ocorrem essas atividades?

E $m$ um segundo momento, procedeu-se a localização das fontes de identificação dos projetos. A ssim, foi fornecida a cópia de cada atividade ou projeto relacionado à saúde. Para a organização das infor mações, procedemos a uso de um roteiro para organização, contendo os seguintes aspectos: denominação do projeto/ atividade; responsável; objetivos; tipo de atividade voltada à saúde; público-alvo; localização geográfica dos estudos. A aplicação de um roteiro norteador objetivou identificar as características gerais e os aspectos de promoção e prevenção inseridos no contexto das atividades, para posterior descrição dos resultados e discussão.

Para a descrição e análise dos dados foi realizado a transcrição das informações coletadas, registrando as falas na íntegra e os resultados obtidos na análise dos documentos, or denadas por ordem cronológica e de acordo com as narrações para posterior análise e interpretação dos resultados.
Concomitante realizamos discussão com a literatura, com fundamentação teórica rel evante ao estudo. A interpretação dos dados obtidos através das falas e interpretação dos documentos foi acrescida de contribuições teóricas consideradas relevantes para fundamentação da análise. Estas atividades acontecer am refl etindo a experiência relacionando a vivência em atividade de saúde no contexto religioso católico no município(13).

D estacamos que os aspectos éticos referente à pesquisa envolvendo seres humanos foram respeitados, incluindo os referenciais básicos da bioética, que inclui a beneficência, não maleficência, autonomia, justiça e equidade ${ }^{(14)}$. A aprovação para realização desta pesquisa foi emitida pelo Comitê de Ética em Pesquisa da U niversidade Federal do Ceará, sob protocolo 110/08. Para realização do estudo, foram esclarecidos os objetivos e benefícios advindos e logo após os sujeitos assinaram o Termo de Consentimento Livre e Esclarecido ( $T$ CLE ), preservando-se a garantia do anonimato. $N$ esse sentido, os participantes foram identificados com a letra " $P$ " e " $C$ " de pároco e coordenador, seguido de um número pela ordem das falas (P $1, C 1$... C3, por exemplo).

\section{RESULT AD OS}

\section{Projetos e atividades da Igreja voltados à saúde}

0 cenário de estudo desenvolve projetos e atividades relacionados à saúde e, segundo o pároco, há ênfase em algumas áreas temáticas, como observamos a seguir:

Aqui na Paróquia, preocupados com 0 alto índice de uso de drogas, buscamos, a exemplo de outra paróquia, o CCE V [ Comunidade Casa E sperança eVida] , nos quais suas atividades são de acompanhamento de viciados e de sua família, incluindo as crianças. T emos ainda a ATAF VT [ A poio a Familiares de Vítimas de T rânsito] , que a póia os familiares depacientes vítimas de acidentes de trânsito e a Pastoral Social que, junto com as mul heres do bairro, desenvolve algumas atividades de saúde (P 1).

No que se refere ao projeto Comunidade $\mathrm{Ca}$ sa E sperança e Vida (CCEV), teve origem em São Paulo há 29 anos. A entidade beneficente atua na área de dependência química (ál cool e drogas) com vistas à prevenção e recuper ação de dependentes 
químicos e seus familiares. No município, o projeto foi implantado em setembro de 2006. Não está ligado a nenhuma instituição ou entidade não governamental, mas trabalha os 12 passos dos Alcoólicos A nônimos (AA). A principal diferença entre esta e outras entidades com funções semelhantes é o cuidado com a espiritualidade. De modo geral, os dependentes participantes do CCEV aprendem a buscar D eus e são inseridos na I greja. Segundo acrescentou um dos organizadores do projeto, segue uma dada organização:

F unciona em uma escola da diocese, localizada no centro da cidade, uma vez por semana, durante duas horas. P ossui 20 coordenadores trabalhando de forma voluntária. A tua nas seguintes áreas: N úcleo de A poio para Toxicômanos e Al coólatras (NATA), N úcleo de A poio para F amiliares de T oxicômanos e A lcoólatras (NAFTA) e N úcleo de A poio para Crianças e F ilhos de D ependentes (NAFT I N HA). F requentam o grupo em torno de 300 pessoas. D esse modo, a população de todo o município é atendida, inclusive a zona rural (C1).

Para seintegrar no grupo, o dependente deve decidir, por sua própria iniciativa, buscar o serviço, reconhecendo sua dependência, conforme descrito pela responsável pelo projeto:

N o primeiro encontro, ele é submetido a uma entrevista individual com um dos coordenadores e somente depois vai para a sala de atividades. A s reuniões são planejadas em São P aulo [ sededo grupo no país] eo planejamento é distribuído para os núcleos. Como observamos, a principal metodologia utilizada éa troca de conversas e desabafos, pois o ponto for te da cura dos dependentes está na possibilidade de falar e desabafar. O u seja, todos têm o direito de se expressarem acerca de seus problemas e exporem seus sentimentos e emoções (C1).

A divulgação das atividades do CCEV é feita no espaço escolar, através dos coordenadores, e nas celebrações das missas que acontecem no segundo sábado de cada mês, nesta também ocorre a entrega de insígnias, cruzinhas, bíblias e, ao mesmo tempo, são relatados testemunhos de forma espontânea. Outra forma de divulgação é no hospital local, que encaminha pessoas atendidas neste serviço caracterizadas como dependentes.

Como principais dificuldades a coordenadora do grupo aponta:
[ ...] a sobriedade de todos os integrantes do grupo, a nossa satisfação pessoal com o trabal ho voluntário e a aceitação das famílias. E ste trabal ho vol untário serve como terapia não somente para os outros, mas para nós e nossa família. A partir do terceiro mês de caminhada, cada partici pante dependente recebe uma cruz, no sexto mês recebe uma bíblia e no nono mês recebe um diploma (C1).

[ ...] a falta de recursos financeiros éuma grande dificuldade, pois os encontros são financiados pelos próprios integrantes, pacientes el ou nós queestamos a frente e, muitas vezes, não são suficientes (C1).

T ais atividades, além de prevenir 0 ag ravo com este grupo populacional, ou seja, com os dependentes químicos, promove a saúde por meio da religiosidade, com al ter nativas de enfrentamento do problema da dependência química. A I greja, com apoio nas atividades do CCE V, também trabalha a família sob o enfoque holístico, desenvolvendo ações no âmbito biológico, espiritual e social.

Quanto à abordagem reabilitadora, identificamos a realizada com os dependentes químicos. Esta dimensão do cuidado é demonstrada por seu principal objetivo, que é de reabilitação, ou seja, com vistas a reinserir a pessoa em dependência química no seu contexto social e prevenir a recaída, configurada pelo resgate para a sobriedade. Conforme evidenciamos, desde o período da sua implantação, em setembro de 2006, 100\% dos participantes se mantiveram sóbrios, sem recaídas. Para a coordenadora do projeto, um dos fatores de maior relevância para 0 alcance deste resultado é a espiritualidade, a fé fortalecida a partir dos encontros e o fato da participação no grupo ser livre e de espontânea vontade do dependente.

Outra estratégia desenvolvida no município é a Associação T ianguense de A poio a F amiliares de Vítimas de T rânsito (ATA F T V), que tem como objetivo apoiar os familiares de vítimas de acidentes de trânsito a conquistas no âmbito pessoal e político. Seu surgimento se deu a partir do interesse, tanto do pároco local, em virtude do al to número de acidentes de trânsito verificados no município, como do atual presidente da associação.

Por ter perdido dois irmãos vítimas de acidente de trânsito, percebi o problema do trânsito em nosso município que, dia-a-dia, faz mais vítimas fatais. A ssim, eu e o padre nos reunimos e fundamos esta associação. As reuniões acontecem no salão paroquial, de acordo com a necessidade, mas a proposta é acontecerem a ca- 
da 15 dias. E mbora o número de associados gire em torno de 30, há a participação de muitos outros voluntários (C2).

Diversas atividades já se concretizaram por meio da ATAFTV, tais como protestos públicos, mediante participação de familiares vítimas de acidentes de trânsito nas principais ruas da cidade; visita à Câmara de Vereadores e reunião com prefeito, pároco e presidente da ATAFVT para sensibilizar estes atores quanto aos recursos orçamentários e investimentos para ações no trânsito; realização de campanhas educativas mensais, desde janeiro de 2008 (incentivo ao uso do capacete, campanhas no carnaval, trabal hos de conscientização com os mototaxistas, fiscalização do Comando de Policiamento Rodoviário); acompanhamento na execução dos projetos aprovados na Câmara.

Entretanto, o presidente desta associação aponta al gumas dificuldades e facilidades neste processo:

Existem dificuldades e facilidades nesse processo. Como dificuldades, a falta de colaboração da sociedade e pouca vontade do poder público; por serem pontos facilitadores, 0 apoio do judiciário e da I greja como for ças importantes neste serviço (C2).

Outra intervenção realizada pela I greja no município é a Pastoral Social, entidade filantrópica que promove atividades sociais com mulheres do município. Esta pastoral foi contemplada com um projeto de financiamento da Cáritas Internacional para implantação de uma Farmácia Viva. Funciona na Promoção da M ulher, espaço da diocese que atendia as mulheres do bairro em situações de vulnerabilidade, oferecendo atendimento de saúde e creche. No entanto, desde 2002 deixou de realizar atividade de atenção direta à saúde e passou a oferecer cursos profissionalizantes para as mães residentes nos bairros adjacentes.

As ações desenvolvidas são relacionadas pela responsável pela pastoral:

[ ...] capacitação, cursos e oficinas para profissionalizar as mulheres e gerar emprego e renda para elas. É financiada pela D iocese, paróquia, governo federal e munici pal. Como atividades realizadas incluem-secursos de cor tee costura, pintura, bordado, bijuterias, além de outros, conforme a demanda (C3).

Q uanto à implantação da F armácia Viva, encontra-se em fase de cultivo das plantas para pos- terior colheita e manipulação dos produtos, com capacitação de mães/ mulheres que frequentam a instituição. No momento estão aguardando recursos financeiros tanto para a aquisição dos equipamentos necessários, como para a capacitação de manipuladoras.

\section{DISCUSSÃO}

Os resultados evidenciam ações interdisciplinares entre a I greja e outras redes sociais de apoio, com vistas à promoção da saúde da comunidade. As atividades e projetos são conduzidos, em sua maioria, por voluntários, sem formação acadêmica, principalmente na atuação com dependentes químicos e seus familiares, mulheres em situação de vulnerabilidade social e familiares vítima da violência do trânsito. Para tal é nítido a urgência de formações específicas para estes trabal hadores.

No estudo, as inter venções preventivas encontradas compreendem medidas adotadas que almejam evitar o surgimento ou agravamento de situações específicas, visando afastar ou reduzir a ocorrência de danos nos indivíduos e coletividades ${ }^{(10)}$. A partir deste conceito identificamos, nos relatos dos coordenadores, atividades de prevenção, embora estas não sejam ligadas diretamente ao sistema e serviços de saúde no município. Como visto anteriormente, as ações desenvolvidas pelo CCEV e ATA FVT são voltadas tanto à prevenção do surgimento de agravos relacionados ao álcool e drogas, quanto às vítimas de trânsito.

Esta prevenção ocorre na I greja, pois a religiosidade é concebida como parte integrante da resolução de problemas e não somente como estratégia de esquiva ou de defesa das pessoas. Assim, retomamos os conceito de religiosidade como adesão às crenças e às práticas relativas a uma I greja ou instituição de religiosidade ${ }^{(1)}$. D essa forma, percebe-se que a I greja pode ser utilizada como espaço de promoção da saúde, tendo em vista sua capacidade de inserção e penetração social.

As experiências citadas neste estudo são exemplos de estratégias de promoção da saúde, já que há como foco a mel horia da qualidade de vida e capacitação da comunidade. Esta compreende 0 processo de construção compartilhada, no qual os setores e/ ou pessoas envolvidos são tocados por saberes que não Ihe são familiares, com vistas à mudança das práticas ${ }^{(15)}$.

A pesar da construção deste processo não contar com 0 apoio dos serviços de saúde, podemos 
considerá-lo como rede de apoio importante, mas que necessita de fortal ecimento com outros serviços e setores do município.

Todas as atividades e projetos desenvolvem ações de educação em saúde, embora de forma pontual, ou seja, campanhas educativas, palestras, oficinas, buscando assim atingir coletivos, não obstante sejam por intermédio de ações muitas vezes isoladas do comprometimento do poder público. A exemplo, campanhas de segurança no trânsito, conhecimento de legislações para acompanhamento de projetos de lei e conhecimento de cultivo de plantas para a implantação de F armácia Viva.

N esse sentido, no que se refere à educação em saúde, é necessário que práticas de ensino-aprendizagem sejam desenvolvidas junto à população, com a finalidade de debater e promover, por meio de reflexão crítica, quanto à tomada de decisão em relação a atitudes e comportamentos de saúde.

Encontramos nas atividades acima relacionadas que, embora realizadas de forma individual, buscam uma mudança de atitude das pessoas com vistas a adoção de comportamento saudáveis da comunidade ${ }^{(16)}$.

A utores criticam que, mesmo com a implantação da Estratégia Saúde da Família, as evidências demonstram a realização de atividades de saúde fragmentadas. Segundo afirmam, estas atuam com grupos de pessoas acometidas por agravos ou com al gumas vul ner abilidades, centradas nas ações e práticas tradicionais ${ }^{(17)}$.

Contudo, os projetos contemplam os princípios da educação em saúde, citando, por exemplo, as atividades voltadas à prevenção de alcoolismo em crianças e familiares, e vítimas de trânsito no município. N esse contexto, é rel evante que os profissionais acreditem que é possível dar um sentido ao que é apreendido pelo indivíduo a partir da consider ação de suas potencial idades pessoais e sociais $^{(16)}$.

Diante destas situações, é preciso trabal har a reabilitação psicossocial, esta compreendida como a oferta de possibilidade ao portador de algum sofrimento. Assim, tem-se a perspectiva de resgatar a cidadania distanciada por muito tempo desses sujeitos, tornando-se, para isso, essencial o envolvimento de todos os profissionais e atores inseridos no contex to do indivíduo ${ }^{(18)}$.

E m consonância com alguns estudos, encontramos principalmente na CCEV uma clara atuação na dimensão do suporte social, sobretudo ao tentar recuperar os indivíduos viciados, ressocia- lizando-0s, resgatando sua fé, sua cidadania, sua vontade de viver, com vistas ao fortalecimento da autonomia e das habilidades dos sujeitos(18,19). Outro aspecto a ser considerado é que, a participação de atividades religiosas pode facilitar a abstenção de atitudes que comprometam a saúde, já que crenças e práticas religiosas proíbem comportamentos relacionados ao uso de álcool e drogas.

A pesar de identificarmos o potencial da I greja em desenvolver ações direcionadas à promoção da saúde e prevenção de doenças, evidenciamos a ausência de maior envolvimento dos serviços de saúde do município. T al fato demonstra a fragilidade na parceria entre estes setores, o que reduz 0 potencial das ações passíveis de atingir um público maior, com consequente impacto positivo para a sociedade.

No entanto, para a Enfermagem, a necessidade de se rever e reaprender o trabalho em saúde é uma constante, reorientando o sentido de sua atuação, que poderá desenvolver a consciência crítica e reflexiva sobre o modo como as pessoas se relacionam, vivem e convivem, e, desta forma, auxiliá-las na resolução dos problemas individuais, comunitários no seu contexto geral(20). $\mathrm{N}$ isso, a inclusão de novos cenários de atuação, tais como a I greja, poderão incrementar sua prática com a obtenção de resultados positivos para a comunidade.

\section{CONSIDERAÇÕES FINAIS}

A partir deste estudo podemos identificar na I greja Católica um possível cenário para o desenvolvimento de ações de promoção da saúde e prevenção de doenças. Com isso, a E nfermagem pode atuar em parceria com este segmento da sociedade, se comprometendo com atividades diretamente ligadas ao estado geral de saúde dos indivíduos.

Estas atividades são de ampla relevância ao bem-estar da população. No entanto, para o profissional de saúde intervir a fim de promover o desenvolvimento da autonomia dos indivíduos na busca da sua saúde ou na melhoria da qualidade de suas vidas, é essencial identificar e fortalecer as redes de apoio estabelecidas com a Igreja, incrementando os ganhos para a qualidade de vida dos indivíduos.

A demais, nessa perspectiva, as políticas públicas devem estar comprometidas com ações que coloquem o indivíduo como protagonista na organização dos processos de produção de saúde. Assim, espera-se construir sujeitos capazes de trans- 
formar seu mundo, melhorar sua saúde e, consequentemente, suas vidas. Para tal, é indispensável contar com os diferentes atores, nos diversos cenários. Todos podem atuar no campo da promoção de saúde de forma efetiva, reduzindo gradativamente atividades assistenciais voltadas somente à doença e intensificando aquel as voltadas à saúde.

\section{REFERÊ NCIAS}

1 Faria JB, Seidl E M F. Religiosidade, enfrentamento e bem-estar subjetivo em pessoas vivendo com HIV/ AID S. Psicol Estud. 2006;11(1):155-64.

2 L ucchetti G, Almeida LGC, G ranero AL. E spiritualidade no paciente em diálise: o nefrologista deve abordar? J Bras N efrol [ Internet] . 2010 [ citado 2010 out 30];32(1):128-32. Disponível em: http:/ / www.scielo. $\mathrm{br} / \mathrm{pdf} / \mathrm{jbn} / \mathrm{v} 32 \mathrm{n} 1 / \mathrm{v} 32 \mathrm{n} 1 \mathrm{a} 20 . \mathrm{pdf}$.

3 Rossi L, Valsecchi A. Dicionário enciclopédico de teologia moral. 3a ed. M adri: Paoline; 1978.

4 Confederação $\mathrm{N}$ acional dos Bispos do Brasil. Diretrizes gerais da ação evangelizadora da I greja no Brasil: 2008-2009. São Paulo: Paulina; 2008.

5 A brahão AL, F reitas CSF. M odos de cuidar em saúde pública: o trabal ho grupal na rede básica de saúde. Rev Enferm UERJ. 2009;17(3):436-41.

6 Ferreira AGN . Círculo de cultura com adolescentes pertencentes a grupos religiosos e a prevenção do HIV/ AIDS [ dissertação] F ortaleza: F aculdade de Farmácia, O dontol ogia e E nfer magem, U niversidade Federal do Ceará; 2010.

7 M eirelles BHS, Erdmann AL. Redes sociais, complexidade, vida e saúde. Ciênc Cuid Saúde. 2006;5(1):67-74.

8 A raújo SSC, F reire D BL, Padilha D M P, Bal disserotto J. Suporte social, promoção de saúde e saúde bucal na população idosa no Brasil. Interface Comun Saúde E duc. 2006;9(18):203-16.

9 T raverso-Y épez M A. Dilemas na promoção da saúde no Brasil: reflexões em torno da política nacional. Interface Comun Saúde E duc. 2007;11(22):223-38.
10 Büchele F, Coelho EBS, Lindner SR . A promoção da saúde enquanto estratégia de prevenção ao uso de drogas. Ciênc Saúde Colet. 2009;14(1):267-73.

110 'Brien M E. Sprirituality in nursing, standing on hold ground. $3^{3}$ ed. Boston:J ones and Bartlett's; 2008.

12 Gil AC. Como elaborar projetos de pesquisa. 4a ed. São Paulo: A tlas; 2006.

13 Ferreira AGN, Vieira NFC, Pinheiro PNC. W hat adolescents think of religious groups on sexuality: action research. O nline Braz] N urs [ I nter net] . 2010 [ cited 2010 Oct 31];9(2). Available from: http:/ / www.objnursing.uff.br/ index.php/ nursing/ article/ view/ 2955.

14 F reitas APA, Silveira NLD. Ética na pesquisa com sujeitos humanos: aspectos a destacar para investigadores iniciantes. Psicol Argum. 2008;26(52):35-46.

15 Campos G W, Barros RB, Castro AM . Avaliação de Política N acional de Promoção da Saúde. Ciênc Saúde Colet. 2004;9(3):745-9.

16 Vidal ECF, Saraiva KRO, D odt RCM, Vieira NFC, Barroso M GT. D emocracia e participação cidadã: um debate sobre as práticas de educação em saúde. Rev G aúcha E nferm. 2008;29(3):475-80.

17 Serapioni M . 0 papel da família e das redes primárias na reestruturação das políticas sociais. Ciênc Saúde Colet. 2005;10(1):243-53

18 Coimbra VCC, Guimarães I, Silva M CF, Kantorski L, Scatena M CM . Reabilitação psicossocial e família: considerações sobre a reestruturação da assistência psiquiátrica no Brasil. Rev Eletrônica Enferm [ Internet] . 2005 [ citado 2010 maio 15];7(1):99-104. Disponível em: http:/ / www.fen.ufg.br/ revista/ revista7_1/pdf/REVISAO_01.pdf.

19 Rostosky SS, Danner F, Riggle ED B. Is religiosity a protective factor against substance use in young adulthood? Only if you're straight!] A dolesc Health. 2007;40:440-7.

20 Kaiser DE, Bianchi F. A violência e os profissionais da saúde na atenção primária. Rev $\mathrm{G}$ aúcha $\mathrm{E}$ nferm. 2008;29(3):362-6.

Recebido em: 11/ 07/ 2010

A provado em: 22/ 11/ 2010

\section{Endereço da autora / Dirección del autor / Author's address:}

Adriana $\mathrm{G}$ omes N ogueira Ferreira

Rua J ose de Alencar, 465, D omingos O límpio

62022-465, Sobral, CE

E-mail: adrianagn2@hotmail.com 